\title{
Magnetostriction of the rapidly quenched Co80Nb8B12 alloy: Dependence on quenching rate, structural relaxation, and temperature
}

\author{
Madurga, V.; Barandiarán, J. M.; Vázquez, M.; Nielsen, Otto V; Hernando, A.
}

Published in:

Journal of Applied Physics

Link to article, DOI:

$10.1063 / 1.338911$

Publication date:

1987

Document Version

Publisher's PDF, also known as Version of record

Link back to DTU Orbit

Citation (APA):

Madurga, V., Barandiarán, J. M., Vázquez, M., Nielsen, O. V., \& Hernando, A. (1987). Magnetostriction of the rapidly quenched Co80Nb8B12 alloy: Dependence on quenching rate, structural relaxation, and temperature. Journal of Applied Physics, 61(8), 3228-3230. https://doi.org/10.1063/1.338911

\section{General rights}

Copyright and moral rights for the publications made accessible in the public portal are retained by the authors and/or other copyright owners and it is a condition of accessing publications that users recognise and abide by the legal requirements associated with these rights.

- Users may download and print one copy of any publication from the public portal for the purpose of private study or research.

- You may not further distribute the material or use it for any profit-making activity or commercial gain

- You may freely distribute the URL identifying the publication in the public portal 


\title{
Magnetostriction of the rapidly quenched $\mathrm{Co}_{80} \mathrm{Nb}_{2} \mathrm{~B}_{12}$ alloy: Dependence on quenching rate, structural relaxation, and temperature
}

\author{
V. Madurga \\ Laboratorio de Magnetismo, Facultad de Fisicas, Universidad Complutense, 28040 Madrid, Spain
}

J. M. Barandiarán

Departamento de Electricidad y Electrónica, Facultad de Ciencias, Universidad del Pais Vasco Lejona, 48080 Vizcaya, Spain

M. Vázquez

Laboratorio de Magnetismo, Facultad de Fisicas, Eniversidad Complutense, 28040 Madrid, Spain

O. V. Nielsen

Department of Electrophysics, The Technical University of Denmark, 2800 Lyngby, Denmark

A. Hernando

Laboratorio de Magnetismo, Faculiad de Fúsicas, Universidad Complutense, 28040 Madrid, Spain

Ribbons of nominal composition $\mathrm{Co}_{80} \mathrm{Nb}_{8} \mathrm{~B}_{12}$ have been prepared by the single roller quenching method using different wheel velocities ranging from 26 to $42 \mathrm{~ms}^{-1}$. X-ray diffraction patterns for ribbons prepared at low velocities show crystalline peaks but characteristic for the amorphous state for samples prepared at velocities above $36 \mathrm{~ms}^{-1}$. Room-temperature values of the magnetostriction constant $\lambda_{s}$ depend on the quenching rate and changes from $4 \times 10^{-7}$ to $-1 \times 10^{-6}$ as the wheel speed increases. Zero magnetostriction samples are obtained at about $34 \mathrm{~ms}^{-1}$. Thermal treatments change the values of the magnetostriction in the same way as a decrease in the quenching rate does. A dependence of the magnetostriction constant on the applied stress has been found. This dependence, fully reversible, is observed at room temperature.

\section{INTRODUCTION}

The magnetostriction constant of Co-rich metallic glasses shows very interesting features. Nearly zero magnetostriction alloys can be obtained by adding small amounts of other metals like $\mathrm{Fe}, \mathrm{Cr}, \mathrm{V}$, etc., to Co-based glasses. ${ }^{1}$ In some of these alloys the magnetostriction constant $\lambda_{s}$ exhibits an anomalous thermal behavior. The compensation temperatures, i.e., temperatures at which $\lambda_{s}=0$, were found for these alloys to be below the Curie temperature. ${ }^{1,2}$ This behavior has been explained by assuming two different microscopic contributions to the macroscopic magnetostriction (single-ion and two-ion) with opposite signs and different variation. ${ }^{3}$ The composition dependence of the one-ion and two-ion contributions has been recently studied in $\left(\mathrm{Co}_{1-x} \mathrm{Fe}_{x}\right)_{75} \mathrm{Si}_{15} \mathrm{~B}_{10}, \quad\left(\mathrm{Co}_{1-x} \mathrm{Ni}_{x}\right)_{75} \mathrm{Si}_{15} \mathrm{~B}_{10}$, ano $\left[\mathrm{Co}_{1-x}(\mathrm{FeNi})_{x}\right]_{75} \mathrm{Si}_{15} \mathrm{~B}_{10}$ glasses. ${ }^{4-6}$ Magnetostriction in such compounds is intimately related to short-range order ${ }^{7}$ and is very sensitive to structural relaxation, depending even on the applied stress, especially in those compositions which have a very low value of $\lambda_{\mathrm{s}}{ }^{\mathrm{B}}{ }^{-11}$

A very special temperature dependence of $\lambda_{s}$ has been reported for the $\mathrm{Co}_{80} \mathrm{Nb}_{8} \mathrm{~B}_{12}$ alloy. ${ }^{12}$ In this compound the magnetostriction constant has a negative values at room temperature but goes to zero as the temperature increases and vanishes in a wide temperature range below the Curic temperature. This behavior has been attributed to a phase change of the crystalline clusters present in the amorphous matrix. Variations of the quenching rate have been used as a tool for studying structural arrangements in some glasses. ${ }^{13}$ In the present work we present magnetostriction measure- ments in $\mathrm{Co}_{80} \mathrm{Nb}_{8} \mathrm{~B}_{12}$ ribbons as a function of the quenching rate, temperature, structural relaxation, and applied stress, in order to get a deeper understanding of this compound.

\section{EXPERIMENT}

Ribbons of nominal composition $\mathrm{Co}_{80} \mathrm{Nb}_{8} \mathrm{~B}_{12}$ were produced by rapid quenching of the melt on a copper wheel spinning at different velocities. The linear speed at the surface of the wheel was changing from 26 to $42 \mathrm{~ms}^{-1}$. More details about the fabrication procedure are given elsewhere. ${ }^{14,15}$

X-ray diffraction was used to check the structure of the as-quenched samples. Figure 1 shows some examples. Sharp crystalline peaks were present for the sampies made at the lower quenching rate, but no known phases were identified. For velocities greater than $36 \mathrm{~ms}^{-1}$ diffraction patterns were characteristic of amorphous materials. Some amounts of crystallinity seem to be present for intermediate quenching rates al hough $x$ ray cannot detect crystals smaller than 100 $200 \AA$. The magnetic moment per atom was determined from the saturation magnetization and density measurements. ${ }^{15}$ No changes were observed in the crystalline samples as compared with the amorphous ones.

The magnetostriction constant was determined by using the well-known SAMR method. The transverse field being produced by an ac current flowing along the ribbon. ${ }^{2,17}$ This allows the sample to be heated by Joule effect, and the temperature dependence of $\lambda_{s}$ can be obtained by measuring at different currents. The temperature of the sample as a function of the ac current intensity was determined from satura- 


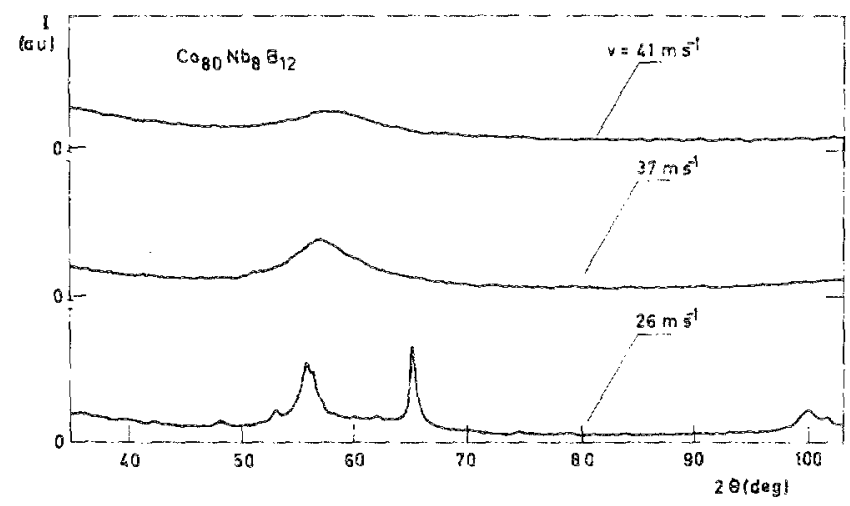

FIG. 1. X-ray diffraction patterns for ribbons produced at different quenching rates, as indicated by the wheel velocity (v). FeKa radiation was used.

tion magnetization measurements as has been reported in detail elsewhere. ${ }^{18}$ The crystallization temperature monitored by coercive force determination is $735^{\circ} \mathrm{C}$.

\section{RESULTSAND DISCUSSION}

Figure 2 shows the room temperature values of the magnetostriction as a function of the quenching rate. A continuous variation from a positive value in the crystalline sample $\left(4 \times 10^{-7}\right)$ to a negative one in the amorphous sample $\left(-1 \times 10^{-6}\right)$ is observed. A change of sign of $\lambda_{s}$ originated by structural relaxation has previously been reported for a nearly zero magnetostriction amorphous compound. ${ }^{2}$ However, the absolute variation of $\lambda_{s}$ shown in Fig. 2 which is about an order of magnitude seems to be rather large to invoke structural relaxation as a possible cause. In order to explain this behavior, it can be assumed that small crystallites, with positive magnetostriction, are clustered in the amorphous matrix which has negative magnetostriction. Crystailine clusters would increase as the quenching rate decreases and compensate the magnetostriction of the amorphous matrix at a wheel speed of about $33 \mathrm{~ms}^{-1}$.

Measurements of $\lambda_{s}$ as a function of the temperature are shown in Fig. 3. The heating current together with the tem-

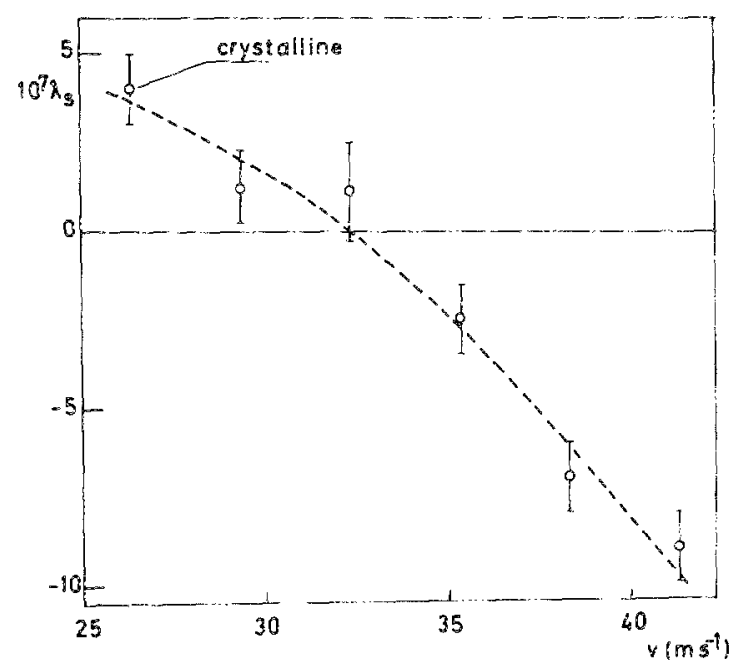

FIG. 2. Room-temperature magnetostriction constant $\left(\lambda_{5}\right)$ as a function of the wheel velocity. The error bars indicate the dispersion found for different pieces of the same batch.

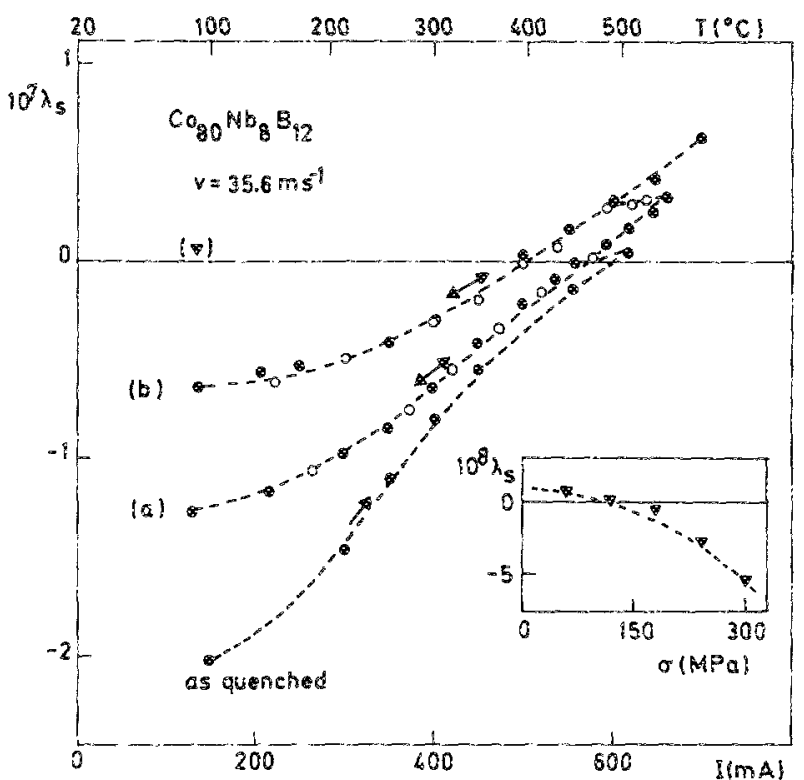

FIG. 3. Temperature dependence of the magnetostriction determined with a load of $80 \mathrm{MPa}$ in a low magnerostriction sample. Full points were obtained on heating and empty ones on cooling. The triangle in bracisets is the value at the end of the treatments. The inset shows the infuence of the applied stress measured at room temperature.

perature of the sample are plotted in the abscissa. An amorphous sample which exhibits a very low value of $\lambda_{s}$ in the asquenched state was used in these measurements. The absolute value of $\lambda_{s}$ decreases as the temperature is raised and a compensation temperature occurs at about $500^{\circ} \mathrm{C}$. This behavior is not reversible, indicating that structural changes have taken place during the heating. After successive heating runs lower values of the compensation temperature are found, and finally a slightly positive values of $\lambda_{s}$ is displayed at low temperature. However, the sample was shown to remain amorphous after the treatments by monitoring the coercive force $\left(H_{e}\right)$.

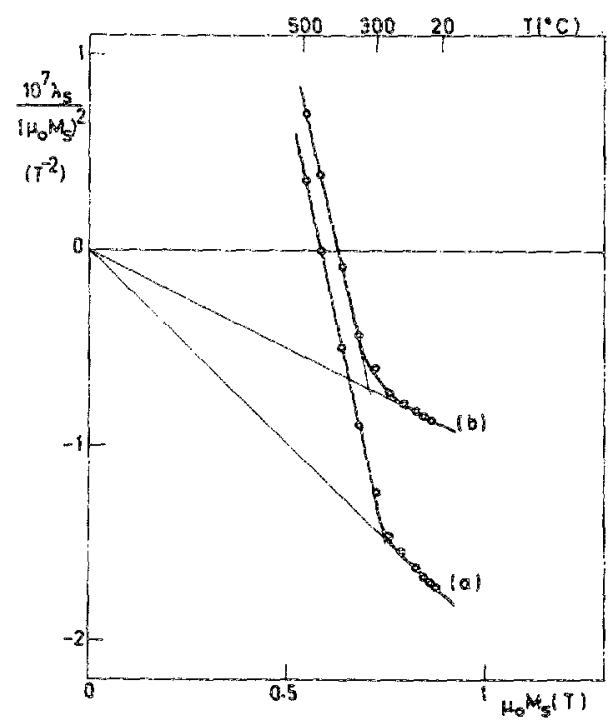

FIG. 4. Points of Fig. 3 replotted to obtain the single-ion and two-ion contributions to the magnetostriction. Labels (a) and (b) refer to the corresponding ones in Fig. 3. 
It is to be noticed that all the values of $\lambda_{s}$ have been obtained with the same, low applied stress of $80 \mathrm{MPa}$. Otherwise no comparison is possible because of the stress dependence of the magnetostriction. As shown in the inset of Fig. 3 the positive value obtained after relaxation becomes negative when higher stress is applied. This dependence of $\lambda$ on $\sigma$ is reversible and is observed at room temperature. Therefore, the influence of a possible stress-induced anisotropy in the variation of $\lambda_{s}$ with $\sigma$ must be disregarded.

As is well known, ${ }^{3}$ the one-ion contribution to the magnetostriction roughly depends on temperature as the cube of the spontaneous magnetization, and the two-ion contribution has a quadratic dependence on the spontaneous magnetization $\left(M_{s}\right)$. The dependence on temperature of the macroscopic magnetostriction can be written as

$$
\lambda_{s}(T)=\alpha\left|\mu_{0} M_{s}(T)\right|^{3}+\beta\left|\mu_{0} M_{s}(T)\right|^{2},
$$

where $\alpha$ and $\beta$ are temperature-independent coefficients. If so, a plot of $\lambda_{s} / M_{s}^{2}$ vs $M_{s}$ will give straight lines from which $\alpha$ and $\beta$ can be deduced. Figure 4 shows such a plot for the reversible parts of the curves in Fig. 3. Reversibility seems to indicate that we are dealing with the equilibrium temperature dependence of the magnetostriction, and no structural relaxation is superimposed. However, Eq. (3) is not obeyed in the whole temperature range. A transition from a low. temperature one-ion behavior to a high-temperature regime involving one-ion and two-ion contributions appears around $300^{\circ} \mathrm{C}$. This fact can be interpreted as arising from a phase transition occurring at this temperature.

The continuous dependence of the magnetostriction between the crystalline and the amorphous state, reported in this work, suggested us to use the nanocrystal concept to account for the observed behavior. This idea was used for explaining the magnetization dependence on temperature in a similar composition. ${ }^{2}$

It remains to be elucidated the microscopic mechanisms giving rise to the complex behavior of $\lambda_{s}$ after annealing. According to our idea possible changes of phase of the crys- tallites, ${ }^{12}$ structural relaxation of the amorphous matrix as well as segregation of new phases may contribute to the $\lambda_{s}$ variations shown in Figs. 3 and 4.

New experiments have to be performed to inquire closely in the origin of the $\lambda_{s}$ evolution with thermal treatment.

R. C. O'Handley and M. O. Sullivan, J. Appl. Phys. 52, 1841 (1981). ${ }^{2}$ A. Hernando, M. Vázquez, V. Madurga, and H. Kronmüller, J. Magn. Magn. Mater. 37, 161 (1983).

${ }^{3} \mathrm{R}$. C. O'Handley, Phys. Rev. B 18, 930 (1978).

"V. Madurga, M. Vázquez, A. Kernando, and O. V. Nielsen, Solid State Commun. 52, 701 (1984).

${ }^{5}$ M. Vázquez, A. Hernando, and O. V. Nielsen, J. Magn. Magn. Mater. 61, $390(1986)$.

${ }^{\circ}$ J. M. Barandiarán, A. Hernando, and O. V. Nielsen, J. Magn. Magn. Mater. $46,317(1985)$.

${ }^{7}$ A. Kernando, V. Madurga, 5. Barandiarán, and O. V. Nielsen, Solid State Commun. 34, 1059 (1985).

${ }^{8}$ A. Hemando, V. Madurga, C. Nûnez de Villavicencio, and M. Vázquez, Appl. Phys. Lett. 45, $802(1984)$.

D. X. Chen and K. V. Rao, Proceedings of the Intermag Conference (1986) to appear in IEEE Trans. Magn.; IEEE Trans. Magn. MAG-22, $451(1980)$.

${ }^{10}$ J. M. Barandiarán, A. Hernando, V. Madurga, O. V. Nielsen, M. Vázquez $I$ and Vázquez II, Phys. Rev. $\mathbf{B}$ (in press).

${ }^{1} \mathrm{G}$. Herzer, Proceedings of the Conference on Sof Magnetic Materials 7, edited by Wolfson Centre, Cardif, England (1985) (unpublished).

${ }^{12}$ B. W. Corb, R. C. O'Handley, S. Paradis, and N. J. Grant, J. Appl. Phys. 55. 1781 (1984).

13P. Allia, F. E. Luborsky, R. S. Turtelli, G. P. Soardo, and F. Vinai, IEEE Trans. Magn. MAG.17, 2615 (1981).

${ }^{14}$ V. Madurga, E. Ascasibar, J. M. González, M. Morala, A. Garcia-Escorial, J. A. Peces, and O. V. Nielsen, Ann. Fis. Ser. B 79, 82 (1983).

:5V. Madurga, M. Lieblich, E. Ascasibar, M. Vázquez, and A. Hernando, Proceedings of the ist Workshop on Noncrystalline Materials, San Feliú de Gijixols, Spain (1986) (to be published).

${ }^{16}$ H. R. Hilzinger, H. Hillman, and A. Mager, Phys. Status Solidi A 55, 763 (1979).

${ }^{17}$ A. Hemando, M. Vảzquez, V. Madurga, E. Ascasibar, and M. Liniers, J. Magn. Magn. Mater. 61, 39 (1986).

${ }^{18}$ M. Vázquez, J. González, and A. Hernando, J. Magn. Mater, 53, 323 (1986). 